\title{
Reflexiones sobre el constitucionalismo español y la Constitución de 1978 (1)
}

\section{Por Carlos Collado Mena}

El objeto de mi conferencia es hablarles de la Constitución española de 1978, que fue refrendada por abrumadora mayoría de españoles el 6 de diciembre de aquel ano, y cuyo quinto aniversario conmemoramos.

Todos ustedes saben que con la sanción por el Rey Don Juan Carlos del Texto Constitucional, sanción que tuvo lugar el 27 de diciembre de 1978, España nacía a la democracia. La Constitución marcó así el deseado tránsito de un Estado autoritario a otro constitucionalista y, por tanto, democrático.

Y acabo de anunciar una dicotomía (autocracia versus constitucionalismo) a la que la moderna politología sociológica atribuye la virtud de servir como base clasificatoria de la tipologia estatal. El profesor Loewenstein, firme introductor del elemento sociológico en la ciencia política, ha sintetizado los rasgos característicos de ambas formas de estado (autocrático y democrático). Permítanme ustedes que se los enumere para comprender brevemente la profunda transformación del Estado español en tan corto espacio de tiempo.

Al igual que los regímenes comunistas o las dictaduras declinantes de hispanoamérica, el régimen polftico que impuso el general Franco fue un régimen autoritario, dentro de la tipología autocrática. Sus caracterfsticas fundamentales eran la existencia de un solo detentador del poder, cuyas prerrogativas no se veían limitadas por la racional y democrática separación de poderes o funciones, y cuya exorbitante potestad le permitió dictar las leyes y ejecutarlas, sin que ningún control, ni popular ni parlamentario, pudiese controlar eficazmente sus acciones. Al contrario, los simulacros parlamentarios de entonces no servían más que para conferirle un patético "placet".

(1) (Conferencia pronunciada por el Presidente de la Asamblea Regional de Murcia, Carlos Collado Mena, en el Ayuntamiento de Melilla, el día 13 de diciembre de 1983). 
Los politólogos dicen que este tipo de organización autoritaria se formaliza casi siempre en una constitución escrita (entiéndase el término constitución entre comillas), cuyas normas son observadas realmente, porque se ajustan a una situación de hecho, como fue la de instituir un poder político sin ninguna legalidad (pues la legalidad vigente estaba regulada por la Constitución de 1931) y cuya legitimidad surgfa de la fuerza de las armas.

El profesor Loewenstein advierte que estas normas constitucionales no son exclusivas de las dictaduras clásicas en nuestro siglo, sino que también son denominador común en los paises comunistas. Adviertan la paradoja de que un sistema totalitario como el soviético se configure bajo la forma republicana y haya establecido una "constitución", que se pretende equiparar a las occidentales.

Los Estados autocráticos pretenden "tapar sus vergüenzas" aprobando unos textos constitucionales hechos a su medida, con el fin de perpetuar el sometimiento de la voluntad popular a la voluntad del dictador o del partido totalitario.

A estos textos se les llama "constituciones semánticas", que no son tales como he dicho antes, sino unas normas cuya realidad ontológica es formalizar una situación de poder político en beneficio exclusivo de los detentadores del poder, que disponen del aparato coactivo del Estado.

A poco que forcemos la imaginación encontramos que a partir de 1939 y hasta el año 1975 ha existido un único detentador del poder, con prerrogativas ilimitadas, encarnado en la figura del general Franco, y que el papel de "constitución semántica" lo han hecho las "normas fundamentales".

En cambio, el constitucionalismo se caracteriza porque es un sistema donde hay varias fuentes de poder, entre las cuales la constitución ha distribuido el ejercicio del poder político, y los cuales están obligados a observar los procedimientos preceptuados por la constitución para formar la voluntad nacional.

El sistema democrático se basa en la legalidad constitucional y en la legitimidad que le confiere el ser expresión de la soberanía nacional, expresada periódicamente a través de las urnas.

Bajo la tipología estatal a la que nos referimos se dan cabida las más dispares formas de gobierno. Ello es posible porque todas tienen unos rasgos comunes, cuyo cumplimiento es inexcusable para que se las considere verdaderas democracias constitucionales, y que a ustedes no les será diff́cil identificar, puesto que los españoles hemos aprendido a apreciarlas y a sentirlas necesarias en los últimos cinco años.

Un primer denominador común es el convencimiento de que el poder emana del pueblo, como reconoce nuestra Constitución. Un segundo, que tanto el gobierno como el parlamento han de estar de acuerdo 
y surgir de la voluntad popular. $Y$ el tercer rasgo, que las elecciones libres y honestas forman un circuito en el que compiten las ideologias y hasta las fuerzas sociales que las promueven.

Esta es en sintesis la diferencia existente entre la autocracia y la democracia, entre el régimen del general Franco y la "joven democracia española", como gustan los occidentales en denominar a España.

Pero no acaba ahí el tránsito político.

Además de este paso se ha dado otro. El Estado anterior, política y administrativamente centralista se ha convertido en un Estado de las Autonomías. Factor éste que considero importantísimo y que merecerá una atención más profunda más adelante.

Retomando el hilo del discurso, es obvio que para que exista una democracia constitucional se precisa la existencia de una Constitución, la cual puede concretarse en un texto escrito o bien cristalizarse en las costumbres y en las convicciones de un pueblo, como ocurre en Inglaterra.

Nuestra historia constitucional, que la hemos tenido y larga, aunque muchos espanoles lo hayan sabido hace poco, dada la permanente ocupación de que ha sido objeto, esta historia, digo, se ha plasmado en textos escritos, en constituciones a menudo usadas como arietes de modernidad y progreso, que en algunos casos han sido eficaces.

Por el contrario, en otras ocasiones han sido utilizadas como armas arrojadizas de unos contra otros provocando la desestabilización del sistema político, y por expansión de la sociedad entera.

Tengo especial interés en resaltar que las constituciones no son un texto eterno e imperecedero. Al contrario, están elaboradas por hombres que durante la etapa preconstituyente se dejan influir por los anhelos, las esperanzas, las reivindicaciones permanente de la sociedad de su época, así como son conscientes de los problemas que sufren y de que no pueden dejarse al margen de la constitución.

Esto nos adentra en una concepción sociológica del constitucionalismo, que se aleja y rechaza de plano aquella vieja idea de que la constitución es el "factotum" para resolver todos los problemas, y que es un código perfecto y encerrado en sí mismo, eterno e imperecedero.

Hijas de su tiempo, las constituciones nacen y mueren con la sociedad que las vio nacer y que las aplicó. Cuando ese modelo de sociedad desaparece por las causas que sean, cuando la evolución social preconiza la obsolescencia de sus formas, entonces las constituciones desaparecen.

$\mathrm{Y}$ entiéndase bien que esta desaparición no quiere decir que la constitución muera y se cambie por otra. Significa que el espíritu que la alentó ya no existe y que la sociedad a la que pretende regular tiene dos opciones. Una, la más radical es cambiar la Constitución. Otra, es interpretarla de nuevo; es decir, reinterpretarla de acuerdo con la nueva sociedad que regula, 
olvidando lo anterior. Esto es lo que han hecho en los Estados Unidos de América, que tiene la constitución más antigua de todo Occidente, data de 1787, y apenas si ha sido modificada.

Para comprender lo que supone la constitución en un sistema democrático quiero citar una frase de Loewenstein. Dice así: "Una Constitución escrita no funciona por sí misma una vez que haya sido adoptada por el pueblo, sino que una Constitución lo es lo que los ostentadores y destinatarios del poder hacen de ella en la práctica."

Bien, expuestas las bases de un estudio sociológico de la Constitución, voy a continuar haciendo un sucinto repaso a nuestra historia constitucional, para pasar a definir los principales rasgos de la Constitución de 1978, centrándonos en su Título VIII y en las diversas soluciones históricas que se han dado al problema regional.

Paso sin más dilación al aspecto histórico.

\section{HISTORIA DEL CONSTITUCIONALISMO ESPAÑOL}

"Hemos predicado tal vez demasiadas constituciones", se lamenta Murillo Ferrol y puede que sea cierto. La Constitución de 1978 es la octava de nuestra historia si excluimos el Estatuto de Bayona de 1808; la Constitución Progresista de 1856, que no llegó a regir; y la Constitución de 1873, que no llegó ni a terminarse.

Ocho constituciones en poco más de un siglo y medio, y cada una se corresponde con las circunstancias sociales y económicas de su época. Ambas interrelacionadas.

Si es difícil, y así lo reconocen la mayoria de los historiadores, encontrar el hilo conductor, un cargamento o teoria que nos explique nuestra trayectoria constitucional; en cambio las corrientes constitucionales parecen estar claras. Martínez Machado opina que "tres grandes corrientes iniciaron, condicionaron o desarrollaron la organización de la estructura política española en las dos últimas centurias". En primer lugar cita las constituciones programáticas (es decir, aquéllas cuya meta fue actualizar, dinamizar o modernizar la sociedad) y al mismo tiempo que variaban en profundidad el sistema de poderes públicos. Entre este tipo se encuentra la de Cádiz de 1812, la de 1869 y la republicana de 1931 .

Una segunda corriente es la de constituciones para todos, que corresponden a transacciones de amplia convergencia doctrinal y política expresadas en un texto constitucional. A juicio de Martínez Machado, a esta corriente pertenecen las de 1837,1876 y la de 1978.

La tercera y última corriente no es precisamente constitucional, sino todo lo contrario. Son los regímenes autoritarios, cuyas características antes he mencionado. Estas van desde el Estatuto de Bayona de 1808 has- 
ta los diversos tipos de leyes fundamentales anticonstitucionales.

Aparte de estas corrientes perfectamente claras, en todas nuestras Constituciones han existido unos rasgos que vuelven a plantearse en cada etapa constituyente. Estas constantes son el regionalismo, las relaciones Iglesia-Estado, la forma de gobierno y las libertades y su garantía. El regionalismo merecerá una atención especial en epígrafe aparte. Veamos ahora cómo han sido afrontadas las tres restantes.

\section{1.-La Constitución de Cádiz de 1812}

La Constitución aprobada por las Cortes de Cádiz en 1812 tiene como dato anecdótico el sobrenombre crítico de "La Pepa", por haber sido promulgada el día de San José. Fue el código político más progresista de Europa y tuvo una notable influencia en las corrientes constitucionalistas del continente. Lástima que en la España de entonces no calara tan hondo, y que su vigencia fuera limitada y con muchos altibajos.

Sus orígenes se remontan a la invasión napoleónica de 1808 y el alzamiento del pueblo madrileño. El esfuerzo francés por reinstaurar la monarquía absoluta contó en todo momento con el rechazo español. La Constitución de 1812 fue el primer intento, aunque frustrado posteriormente, de erradicar el Antiguo Régimen para implantar un sistema político-constitucional de corte progresista y moderno.

Fue una constitución de corte popular, elaborada sin la presencia del Rey, aunque más adelante fue impuesta a Fernando VII y Doña María Cristina. Sus 384 artículos la convierten en la constitución más larga de nuestra historia. $Y$ tal amplitud se explica porque regulaba sistemáticamente la organización de poderes del Estado y los derechos de los espanoles, entre otras cosas.

Pasemos ahora a examinar cuáles eran los principios que la inspiraron y que nos dan una idea del avance social que se pretendió lograr con ella.

En primer lugar, proclamó el principio de soberanía nacional. En el Antiguo Régimen la soberanía se atribuía exclusivamente al Rey. En el Estado moderno, al pueblo. Su artículo 3 dice asi: "La soberanfa reside esencialmente en la Nación y por lo mismo pertenece a ésta exclusivamente el derecho de establecer sus leyes fundamentales." Este principio se convirtió en el valor político por excelencia de la constitución y ha sido recogido por todos los textos constitucionales posteriores con carácter progresista.

El segundo principio en la división de poderes. La teoría de Montesquieu, que divide las funciones estatales en legislativas, ejecutivas y judiciales, fue recogida íntegramente por la Constitución de 1812. 
El tercer principio esencial fue el nuevo concepto de representación. Los Diputados ya no van a representar a electores o estamentos concretos, sino que van a crear por sí mismos la voluntad nacional.

Este código moderno fue derogado por Fernando VII en 1814, tras su vuelta del exilio, por considerarla atentatoria contra la dignidad del monarca. Esta derogación supuso la vuelta al régimen absolutista, que se prolongó hasta 1820.

Este año triunfó el pronunciamiento de Riego en Cabezas de San Juan y se restableció la Constitución de Cádiz, que reguló la vida del país hasta 1823, fecha en la que acab6 el trienio constitucional. El 1 de octubre Fernando VII recobró los plenos poderes y declaraba nulos los actos del gobierno constitucional. Finalizó de esta forma la aplicación de la Constitución de Cádiz, aunque es de resaltar que dejó una huella indeleble en el constitucionalismo español. Pero tuvo ante sí un reto demasiado grande: erradicar el Antiguo Régimen, cuando el pueblo todavfa no había asimilado los nuevos mecanismos de gobierno ni se había identificado con las instituciones constitucionales.

\section{2.-El Estatuto Real de 1834}

Tras la década absolutista en la que reinó Fernando VII, Doña María Cristina de Borbón fue nombrada Gobernadora del Reino durante la minoría de edad de su hija Isabel II. La regencia quedó constituida al hacerse público el testamento de Fernando VII el tres de octubre de 1833.

Como buena monarca absolutista, la Reina Gobernadora firmó un Manifiesto por el que se pretendía volver al despotismo ilustrado, cuyo ideario se resume en el célebre aforismo de "todo para el pueblo pero sin el pueblo". Lo que era muy diff́cil de conseguir después de institucionalizar la soberania nacional.

Por eso, María Cristina tuvo que ceder y le encargó al liberal Martínez de la Rosa la preparación de un nuevo texto constitucional, en el que intervino Javier de Burgos, responsable del decreto que dividió Espana en provincias, tal como actualmente las conocemos, división de la que este af́o se cumple el 150 aniversario.

Las principales características del Estatuto Real de 1834 son su carácter de constitución otorgada, incompleta y breve, y flexible. Fue otorgada porque hubo una cesión de poderes monárquicos, hecha a iniciativa de la Regia Gobernadora, aunque Alcalá Galiano señaló que las presiones recibidas por María Cristina convierten el Estatuto en una concesión arrancada por la opinión pública. Encontramos aquí el elemento sociológico de toda con- 
figuración de poder. Antes se dijo que los poderes constituyentes no podían obviar al impulso social y sus aspiraciones si querían que el fruto de su trabajo tuviese una mínima aceptación popular. Se sienten aquf las huellas que la Constitución de Cádiz dejó en los españoles de la época.

El Estatuto era breve e incompleto porque se limitaba a regular la organización de las Cortes, divididas en dos Cámaras o Estamentos (el de Próceres y el de Procuradores) y sus relaciones esenciales con el rey. Faltaba sobre todo una declaración de derechos, inherente a la esencia constitucional desde la Revolución Francesa.

La soberania nacional se habia eliminado. Con el nuevo texto, la soberanía era conjunta y correspondía al rey y a las Cortes. No proclamaba tampoco la división de poderes, aunque la reconocía de manera implícita. Su ideología era moderada y conservadora, pretendiendo conjugar el orden con la libertad, la tradición con las nuevas ideas. La sombra de la Constitución de Cádiz aparece una vez más en los intentos constitucionales posteriores.

Valorando el Estatuto Tomás Villarroya dice que "significó el fin definitivo del Antiguo Régimen en España". Estableció un sistema representativo nuevo, pues bajo su vigencia se celebraron las primeras elecciones directas en España. E instituyó el bicameralismo, que duraría hasta la Constitución de 1931, e institucionalizado en la de 1978 .

Pese a todo, los liberales no perdonaron la erradicación del principio de soberania nacional, fundamental en un sistema constitucionalista tal como lo entendemos hoy en día. Tampoco olvidaron la ausencia de una declaración de derechos.

El Estatuto creó un régimen político que quebró al cabo de dos años. En el verano de 1836 se inició en Málaga un pronunciamiento propagado de provincia en provincia, que culminó con el motín de La Granja, obligando a la Reina Gobernadora a aceptar la Constitución de 1812.

\section{3.-La Constitución de $\mathbf{1 8 3 7}$}

En el verano de 1836 se levantaron las Juntas en contra del Estatuto y a favor de restablecer la Constitución de Cádiz. Esta era considerada como bandera de libertad y símbolo de soberanía nacional. El Gobierno de Calatrava convocó a elecciones a Cortes, las cuales se reunieron en octubre de aquel año. De esas Cortes nació la Constitución de 1837, que no fue una reforma de la de Cádiz, sino un texto distinto.

Entre sus características figura el ser una Constitución de origen popular, en la que se consigna expresamente la soberanía nacional.

Recogía los principios esenciales de la Constitución de 1812, pero con matizaciones que afectaban a su sentido y alcance. En primer lugar, 
sacó la alusión a la soberanía popular del articulado al preámbulo; frente a la rígida separación de poderes establecida por la Constitución de 1812 , la de 1937 articuló unos principios de colaboración e interacción entre ellos, propia de un sistema parlamentario.

La de 1937 fue una constitución de transacción doctrinal, entre la de 1812 y el Estatuto Real. Se remitía constantemente a las leyes ordinarias para regular las instituciones y los derechos que proclamaba, con el fin de conseguir un texto que permitiera el gobierno de conservadores y liberales. Pero no se hizo buen uso de este mecanismo y resultó incumplida. Balmes en 1844 dijo que "La Constitución no se ha observado en tiempo de guerra ni en tiempo de paz, ni durante la Regencia de la Reina Madre ni durante la de Espartero, ni tampoco desde la declaración de mayor de edad de doña Isabel".

Volvemos al factor sociológico, sin el cual no se puede comprender el constitucionalismo. Es obligado repetir aqui la frase antes citada de Loewenstein, en el sentido de que un Estado para ser constitucional necesita que tanto los gobernantes como los gobernados asuman los principios y reglas constitucionales y que las cumplan. De lo contrario, la constitución se convierte en un texto mejor o peor redactado, pero sin valor.

En aquella época comenzaron a aparecer escritos donde se ponía en tela de juicio el valor y las virtudes mágicas que se le hablan atribuido a la Constitución. E incluso se llegó a cuestionar si el sistema constitucional era viable entre nosotros. El tiempo se ha encargado de demostrar que sí, cuando el pueblo ha asumido y cumple los mecanismos constiucionales.

\section{4. - La Constitución de 1845}

Por 1843 entre moderados y progresistas surgió la necesidad de reformar la Constitución de 1837 y levantarse contra el general Espartero, esto fue motivo de una unión entre ambas corrientes ideológicas contrarias y enfrentadas.

En mayo de 1844 Narváez se hace cargo del Gobierno y se propone llevar a la reina la reforma y mejora de la Constitución del Estado.

La revisión que se hizo no fue profunda ni sustancial, y tuvo en contra a fracciones de progresistas y moderados que no veían la conveniencia de reformar la Constitución de 1837. Al final se aprobaron algunas modificaciones. El texto de 1845 eliminaba toda referencia a la soberanía popular, conteniendo un nuevo preámbulo en el que se decía que la Corona, en unión y de acuerdo con las Cortes, decretaba y sancionaba la nueva Constitución. Era una constitución "pactada" entre el pueblo y el rey, en la que no se reconocía que la soberanía resid la en el pueblo, sino que daba a entender que era compartida por la Corona y las Cortes. 
En 1845 las Cortes habian perdido la potestad de autorizar por ley el matrimonio del monarca, según disponía la Constitución de 1837. Ahora, el rey no tenía más que notificar a las Cortes su matrimonio, las cuales sólo debían aprobar las estipulaciones y contratos matrimoniales.

La institución de la tutela real también había variado de un texto a otro. Las Cortes ya no estaban legitimadas para establecer la regencia, sino que eran los parientes más próximos del rey menor o incapaz los llamados a la tutela legítima, sólo de forma subsidiaria podía acudirse a la tutela electiva.

En cuanto al Senado, también hubo modificaciones. No se quería, por imposible, un Senado nobiliario y hereditario, pero tampoco un Senado electivo. En esta segunda intención habra pasado la experiencia negativa del Senado tal como lo configuraba la Constitución de 1837. Por eso se estableció en 1845 un Senado con-las siguientes características: el rey nombraba a los senadores de entre unas clases sociales o profesionales determinadas; el número de senadores era ilimitado y su cargo vitalicio.

La duración del mandato al Congreso se amplió de 3 a 5 años, pretendiendo con ello dar una mayor estabilidad a la vida de las Cortes. Pero esta previsión fue inútil pues las disoluciones anticipadas de las Cortes fueron frecuentes durante la vigencia de la Constitución de 1845. En el cuarto de siglo que estuvo en vigor se celebraron diez elecciones y sólo dos Congresos culminaron el mandato de cinco años.

En cuanto al funcionamiento de las Cortes, se suprimió la obligación de constituirlas al menos una vez al año, si el monarca no lo hacía antes. Esa obligatoriedad fue considerada como una desconfianza ante el rey. Observamos aquí que todas las modificaciones habidas en 1845 respecto a la Constitución de 1837 suponen una merma de la soberanía nacional y un aumento de las prerrogativas del monarca.

Esta marcha atrás seguía sin satisfacer al país. La esperanza que suscitó la subida al trono de Isabel II pronto comenzó a desvanecerse. La firmeza de los gobiernos no era grande y las Cortes llevaron una vida desigual. La corrupción electoral y la falsificación del sufragio se acrecentaron. En definitiva, las instituciones políticas seguian sin satisfacer las necesidades del país.

Por ello, Bravo Murillo en 1852, siendo presidente del Gobierno, preparó una reforma constitucional que culminara la actuación llevada a cabo en otros frentes desde un año atrás. La reforma consistía en un proyecto sumario de Constitución, acompañado de ocho leyes orgánicas sobre la organización del Senado, las elecciones de diputados, el régimen interior de las Cortes, las relaciones entre las dos Cámaras, seguridad individual, seguridad de la propiedad, orden público y grandezas y títulos del reino.

Los textos de Bravo Murillo modificaban esencialmente los supuestos del régimen constitucional tal como se venía desenvolviendo en España 
y pretendian legalizar el predominio del Ejecutivo; restringiendo la autonomía parlamentaria y reduciendo la actividad y funciones de las Cortes.

Isabel II ante la oposición de progresistas y moderados retiró en diciembre de 1852 su confianza en Bravo Murillo, con la cafda del gabinete el proyecto constitucional cayó en saco roto.

\section{5.--La Constitución de 1869}

En 1864 la reina había perdido ya el respeto de las figuras políticas, por su ligereza en los asuntos de gobierno, y su evanescente vida privada. Los partidos políticos se fueron alejando del Trono, el cual quedó completamente aislado. En 1866 el partido progresista, alejado de la vida pública legal tres años atrás, se une a los demócratas para derribar en común el Trono de Isabel II, y todo el sistema establecido. Ese mismo año, la reina despidió a O'Donnell, jefe del Gobierno y de la Unión Liberal. Sólo le quedaba, pues, el apoyo del partido moderado, que cayó al morir Narváez en abril de 1868.

Los conjurados dentro y fuera de España aunaron sus esfuerzos, y bajo el liderazgo de Prim iniciaron en Cádiz una revolución que pronto se extendió a toda España, y que es conocida por "La Gloriosa".

La revolución provocó la caída de la reina, y a punto estuvo de hacerlo con la Monarquía. Este impulso revolucionario llevó a la República de 1873, pero antes estuvo en vigor la Constitución de 1869.

Lo primero que se observa en el nuevo texto es el rechazo a la de 1845. En efecto, sensiblemente influido por la Constitución belga de 1831 y por la americana de 1787 , la española de 1869 es de origen popular, decretándose en su preámbulo que la nación española y en su nombre las Cortes, elegidas por sufragio universal, decretaban y sancionaban la nueva Constitución.

Con todo, su rasgo más característico era la atención prestada a los derechos individuales, cuya declaración se contiene en el Título I. Las presiones sociales y las esperanzas populares llevaron a los constituyentes a elaborar un texto constitucional que realmente recogiera los anhelos de la época, entre los que figuraban el reconocimiento y la protección de los derechos de cada individuo frente a los demás y frente al Estado.

La Constitución regulaba generosamente todos y cada uno de los derechos que reconocía.

Subyacía la preocupación de lo ocurrido bajo constituciones anteriores, que proclamaban un derecho, pero no lo regulaban, sino que se remitían a una ley, la cual no llegaba a elaborarse. La Constitución rehuía a todo lo que supusiera una traba inferior al ejercicio de los derechos.

La Constitución de 1869 reconocía la libertad de cultos, su artículo 
21 garantizaba a los españoles que profesasen una religión distinta de la católica y a los extranjeros residentes en España, el ejercicio público y privado de cualquier culto, sin más limitaciones que las reglas universales de la moral y el Derecho. Se recogía así una vieja aspiración revolucionaria. La aprobación de este artículo dejó su huella, hasta el punto que la libertad o no de cultos han sido banderas posteriores de corrientes ideológicas bien distintas, que podfamos calificar en terminologia moderna como progresistas y reaccionarios.

La Constitución de 1869 también reconocía el sufragio universal, mientras que las constituciones anteriores a la revolución permitían el voto a aquellos que poseyeran determinados bienes o estudios. La consagración constitucional del sufragio universal fue considerada como la mayor conquista de la "Gloriosa Revolución". Fue el primer paso hacia un régimen verdaderamente democrático, tal y como hoy se entiende.

Se reconocían también el derecho de reunión y de asociación. Derechos modernos y que dan una idea del talante de los redactores de la Constitución.

Las Cortes se configuraron bicamerales, con el fin de que estuvieran representados los intereses locales junto a los generales.

El rey tenía unas atribuciones parecidas a las de anteriores constituciones. Era inviolable, tenfa iniciativa legislativa y facultad para sancionar las leyes, nombraba y separaba libremente a sus ministros, y su autoridad se extendía en materias de orden público interior y conservación de la seguridad exterior. No obstante, pese a estas coincidencias con textos constitucionales anteriores, se pretendía que el espiritu de la Monarquía fuese distinto, de signo democrático. El 16 de noviembre de 1870 las Cortes eligieron rey de España a Amadeo de Saboya por 191 votos a favor de un total de 344 diputados.

La llegada del nuevo rey resultó inoperante, por su condición de extranjero, para frenar las fuerzas surgidas de la revolución de 1868 . La Constitución liberal no podía ser un freno eficaz para la expansión de esas fuerzas, y sus preceptos fueron sacrificados enseguida para acometer la imposible misión de buscar el orden público.

El marasmo de la vida política española era tal, que Amadeo de Saboya renunció a la Corona para sí y para sus descendientes en un mensaje dirigido al presidente del Consejo de Ministros en febrero de 1873. La propuesta fue aceptada por el Senado y el Congreso. Ese mismo día, se presentó una moción firmada por Pi y Margall, Salmerón y Figueras en la que se decía que la Asamblea Nacional reasume todos los poderes y declara como forma de Gobierno de la Nación la República, dejando a las Cortes constituyentes la organización de esta forma de Gobierno.

Se constituyó así la Primera República, que no derogó formalmente la Constitución de 1869, y se entendió que tácitamente continuaría en vi- 
gor hasta que no se promulgase la Constitución republicana, la cual nunca vio la luz.

La idea del Estado federal habra arraigado en las filas republicanas, y esa idea se recogió en el proyecto de 1873 . El cual, por otra parte, respetaba los derechos consagrados en 1869 y completaba la libertad de cultos con la separación entre Iglesia y Estado. En la parte orgánica consagraba el principio de separación de poderes, estableciendo un poder de relación entre ellos, confiado al presidente de la República. Pese a ello, la verdadera novedad era la configuración del Estado Federal que hacía el proyecto de 1873. Esta configuración la trataremos con más detalle en el apartado dedicado al problema regional.

El proyecto decía en su artículo primero: "Componen la Nación española los Estados de Andalucía Alta, Andalucra Baja, Aragón, Baleares, Canarias, Castilla la Nueva, Castilla la Vieja, Cataluna, Cuba, Extremadura, Galicia, Murcia, Navarra, Puerto Rico, Valencia, Regiones Vascongadas." En definitiva, se consideraban nuevos Estados los antiguos reinos de la monarquía, con algunas modificaciones y la exclusión de León.

El artículo segundo del proyecto decía que los establecimientos de Africa a medida de sus progresos se elevarán a Estados por los poderes públicos. No se olvidó el viejo proyecto de las posibles reivindicaciones de las plazas en Africa bajo la soberanía española.

El proyecto fue depositado en las Cortes sin que éstas pudiesen discutirlo. A lo largo de 1873 la anarquía y el desorden experimentaron una espiral incontenible. En ese mismo año se sucedieron cuatro presidentes de Gobierno. Hubo el levantamiento cantonal en Levante (especialmente en Cartagena) y Andalucía. El país se fragmentó en pequeños territorios y perdió su articulación.

El tres de enero de 1874 el general Pavía acabó sin resistencia con la República Federal y se reiteró el vigor de la Constitución de 1869. Durante un año se vivió un régimen provisional, durante el cual volvió el orden y se disminuyeron las tensionés. Era el camino de la Restauración.

\section{6.-La Constitución de $\mathbf{1 8 7 6}$}

Alfonso XIII fue proclamado rey de España en diciembre de 1874, con la oposición de carlistas (que seguían sin reconocer la legitimidad de Isabel II) y por los republicanos más furibundos. El verdadero artífice de la Restauración fue Cánovas del Castillo, que habia preparado el terreno conciliando voluntades, apagando recelos y difundiendo la idea de que sólo una monarquía renovada podría traer consigo la paz.

En principio se pensó mantener en vigor la Constitución de 1869 , pero pronto se convino que era necesario un nuevo texto constitucional para la 
nueva época que comenzaba la nación.

Cánovas, presidente del Gobierno, reunió a 600 antiguos senadores y diputados, procedentes de todas las Cámaras legislativas de $\mathbf{3 0}$ años atrás. Pretendía que elaboraran una constitución que recogiese las tradiciones y enseñanzas de nuestra historia constitucional. De esa reunión surgió una comisión de notables, compuesta por individuos de varia afiliación ideológica, que debía preparar las bases del nuevo texto constitucional.

El 30 de junio de 1876 nació la nueva Constitución, que desde el primer momento fue considerada un pacto o acuerdo entre la Corona y las Cortes. Se eliminaba de esta forma la doctrina de la soberanía nacional proclamada en la Constitución de 1869 y se volvía a la doctrina de la soberania conjunta del rey y las Cortes. En el texto de 1876 se recoge por última vez en nuestra historia constitucional la doctrina apuntada por el Estatuto y continuada en 1845: la potestad real y la representación nacional, lejos de contraponerse, se conjugan y complementan entre sí, ninguna tiene poder sobre la otra.

La nueva Constitución fue definida como completa y ordenada. Su mejor virtud fue una redacción frecuente y calculadamente ambigua, que se remitía a las leyes ordinarias para regular determinadas materias, y que permitió el gobierno alternativo de partidos distintos, los cuales realizaron políticas diferentes.

No obstante, recortaba el reconocimiento y la garantía de los derechos individuales, proclamaba derechos cuya regulación se remitía a leyes ordinarias, que a veces recortaron su ejercicio, suprimía la libertad de cultos y no permitía celebrar ceremonias externas de otra religión que no fuera la católica, que era la del Estado, no hablaba del sufragio universal, y concedía muchas posibilidades al Gobierno para suspender los derechos individuales.

En cuanto a su aplicación, cabe resaltar que la Constitución de 1876 ha sido la de más larga duración en la historia espanola. Bajo su vigencia se consiguió cierta regularidad en la vida política. Duración y regularidad que se debieron en gran medida a su carácter transaccional.

El éxito de todo ello se le atribuye a Cánovas, quien formando parte de un partido conservador, al estilo británico, propició la creación de otro liberal, presidido por Sagasta, con el objeto de instituir el bipartidismo y la alternancia en el poder. El actual líder de la oposición, Manuel Fraga, ha repetido en varias ocasiones que a él le gustaría ser un nuevo Cánovas, y crear un sistema bipartidista. En aquella ocasión dio resultado un tiempo y se equilibró el ejercicio del poder, aunque el régimen parlamentario quedase convertido en una ficción.

El juego quebró durante el reinado de Alfonso XIII. A principios de este siglo se inicia lentamente la desintegración del bipartidismo. En 1909, el rey presionado por los liberales provocó una crisis del Gobierno presidi- 
do por Maura, sucesor de Cánovas, y el partido conservador se fragmenta en mauristas, datistas, ciervistas y otras multiplicaciones que vinieron con el tiempo. El partido liberal siguió una trayectoria parecida. La herencia de Sagasta, el cual fue asesinado y su partido se dividió en romanistas, prietistas, albistas, etc.

Entre 1902 y 1923 se sucedieron 33 gobiernos, de los cuales sólo cinco duraron más de un año. La descomposición interna era irreversible. El malestar obrero desembocó en huelgas generales. La inquietud revolucionaria, el desorden y la situación de Marruecos desembocaron en el golpe de Estado de Primo de Rivera, en septiembre de 1923. El rey le entrega el poder y se establece así la dictadura que llegó hasta 1930.

En los primeros días de la dictadura se suspendió la Constitución de 1876, el Gobierno fue sustituido por un Directorio Militar, al frente del cual estaba Primo de Rivera, quien suspende los derechos individuales y cesa a los presidentes del Congreso y del Senado.

El propio dictador propició un proyecto constitucional en 1929 , en el que se hablaba de leyes orgánicas del Consejo del Reino, de las Cortes y del poder ejecutivo y judicial.

El rey acogió con frialdad el proyecto, y los políticos del régimen, sin entusiasmo. En 1929 la dictadura habia perdido apoyo popular e impulso político, se encontraba en su recta final.

\section{7.-La Constitución de 1931}

La dictadura de Primo de Rivera cayó en el afío 1930, y el rey nombró presidente del Gobierno al general Berenguer. El 16 de febrero de 1931 le sustituyó el almirante Aznar, quien convocó elecciones municipales para el 12 de abril. Estas elecciones fueron interpretadas como el refrendo de la institución monárquica, por eso cuando el número de concejales monárquicos elegidos fue sensiblemente inferior al de los republicanos, se entendió que el resultado era desfavorable al rey y a la monarquia.

De esa manera, el 14 de abril se proclamó la Segunda República, y el Gobierno provisional encargó la redacción de un proyecto constitucional, cuyas disensiones motivaron el que las Cortes encargara el cometido a una comisión presidida por Jiménez de Asúa.

La Constitución se aprobó el 9 de diciembre de 1931 y fue controvertida desde el principio, ya que ofrecía nuevas soluciones a problemas primordiales, como la confesionalidad del Estado, las reivindicaciones regionales, la enseñanza, etc. Problemas que hemos visto se repiten como una constante en nuestra histora.

La Constitución atendía con extensión el capftulo de los derechos in- 
dividuales, tradicionales en la historia constitucional de nuestro país. Además, recogía y protegía especialmente el derecho al trabajo y a la cultura, y tutelaba, junto a los derechos de la persona, los correspondientes a instituciones personales o no, como la familia, los sindicatos y las asociaciones de todo tipo.

En el aspecto religioso, la Constitución declaraba que el Estado no tenía religión oficial, proclamaba la libertad de culto, decretó la ensefianza laica, consagró formalmente el divorcio, etc. Ello supuso una conmoción en los sectores conservadores, que crisparon los ánimos de la época.

En cuanto al problema regional, latente desde muchos años atrás, por las reivindicaciones de Cataluña sobre todo, fue resuelto de forma ambigua. El Estado no era ni unitario ni federal, sino que se le designaba con el nombre de Estado Integral, y reconocía el derecho a la autonomia de ciertas nacionalidades, como Cataluña, País Vasco y Galicia, y de otros territorios que lo solicitasen.

El aspecto social se incardinó definiendo la nueva República como una república de trabajadores de todas clases. Se protegió especialmente a las clases menos favorecidas cultural y económicamente, como medio para solucionar las grandes desigualdades que existían entre las capas sociales de entonces.

La nueva organización del legislativo se hizo partiendo de la necesidad unicameral, que ya se recogió en la Constitución de 1812 y en el proyecto de la Primera República. El "padre" de la Constitución, Jiménez de Asúa, defendió la unicameralidad diciendo que la dualidad de las Cámaras debilitaría el parlamento, ya que éste descansa en el principio de igualdad y una segunda Cámara podría romperlo.

La Constitución de 1931 conced fa en principio una mayor autonomia a las Cortes, las cuales se reunirian sin necesidad de convocatoria el primer día hábil de los meses de febrero y octubre de cada año, y funcionarían, por lo menos, tres meses en el primer período y dos en el segundo. Además, se regulaba la Diputación Permanente, que respondía a la necesidad de asegurar las funciones y poderes de la Cámara cuando ésta estuviera en períodos intersesiones o disuelta.

Con todo, la gran novedad fue la figura del presidente de la república, cargo que ocupó primero Alcalá Zamora. El procedimiento ordinario para elegirlo era la votación del Congreso y de un número de compromisarios igual al de diputados. Los compromisarios se elegían por sufragio universal, libre y secreto. El primer presidente elegido por este procedimiento fue Azaña, y la duración de su mandato era en teoría de 6 años.

El presidente de la república nombraba y separaba libremente al presidente del Gobierno y, a propuesta de éste, a los ministros. El presidente podía asimismo disolver las Cortes dos veces como máximo durante su mandato. 
De acuerdo con el artículo 83 de la Constitución, el presidente de la república podía pedir al Congreso que antes de promulgar las leyes las sometiese a nueva deliberación, si tales leyes volvían a ser aprobadas por una mayoría cualificada de dos tercios de diputados, el presidente quedaba obligado a promulgarlas.

Como vemos, al presidente de la república se le reconocían unos derechos y potestades grandes, de tal manera que podía incidir en casi toda la vida política de la república. Esas facultades le hacian ser un buen blanco de críticas y rechazos, como sucedió con Alcalá Zamora.

El Gobierno tenia menos prerrogativas. Habla de contar con la confianza del presidente de la república y de las Cortes, con lo cual las tensiones pod ian ser superiores.

Con la perspectiva que da el paso del tiempo, se puede decir que la Constitución de 1931 se proponf́a establecer unas reglas de juego, que en ocasiones fueron quebradas y olvidadas por los mismos protagonistas, lo que supuso el resquebrajamiento del régimen que intentaba regular.

Las tensiones religiosa, regional y social, provocaron un clima de enfrentamiento que dificultó las tareas de gobierno y que propició el golpe de Estado del general Franco y el paso a un sistema autoritario, en el que no se reconocía expresamente los derechos individuales ni se permitía a los ciudadanos expresar sus opiniones políticas a través de las urnas, ni de ningún otro medio. El dictador acabó con el principio de soberanía popular y la democracia fue aniquilada en favor de un sistema autocrático, negador de los derechos y libertades internacionalmente reconocidos como básicos para el desarrollo de la persona y de la convivencia de un pais.

\section{LA CONSTITUCION ESPANOLA DE 1978}

A la muerte del general Franco, en noviembre de 1975, se acelera en España un proceso de cambio político, iniciado algunos años antes, que desemboca en las elecciones legislativas convocadas de acuerdo con la Ley de Reforma Política (15 de diciembre de 1976), aprobada mediante referéndum; elecciones que tienen lugar el 15 de junio de 1977. De ellas nace un parlamento bicameral que desde el verano de ese affo al otoño del siguiente elabora lo que será el texto de la Constitución, que fue refrendado el 6 de diciembre y cuyo quinto aniversario conmemoramos hoy.

La Constitución de 1978, la actual Constitución espanfola es larga, la segunda después de la de 1812 . Establece por primera vez en nuestra historia la monarquía constitucional y parlamentaria, configura el Estado como social y democrático de derecho, reconoce el derecho a la auto- 
nomfa de nacionalidades y regiones, reconoce por primera vez en nuestra historia constitucional la existencia de partidos políticos (que antes no se mencionaban en el texto de la constitución) y, en resumen, ofrece un amplio catálogo constitucional de derechos y libertades, adecuados a nuestro tiempo y algunos de los cuales se consideran pioneros en el constitucionalismo occidental.

La Constitución corresponde, sin duda, a la peculiaridad hispánica de "pacto o transacción constitucional", como ha indicado Martínez Cuadrado. Es decir, un texto convenido por una representación amplia de fuerzas políticas tras unas elecciones generales de signo formalmente no constituyente, pero que en la práctican-decretan la Constitución. Al comienzo del sistema democrático, esta convergencia fue llamada "consenso", palabra que se repetía, y a la que se le confería poderes casi taumatúrgicos.

Fruto de ese consenso es el que la Constitución de 1978 no haya suscitado controversias o entusiasmos tan graves y rotundos como los que despertaron las constituciones programáticas de 1812, 1869 ó 1931. Por ello también se ha calificado de ambigua, sobre todo en el Título VIII que regula la organización territorial del Estado. Si bien es verdad que cierto grado de ambigüedad es necesario para hacer un texto que tenga visos de perdurar y adaptarse a las nuevas necesidades de tiempos venideros, que los constituyentes de hoy no pueden prever.

Para finalizar esta introducción al texto por el que hoy nos regimos, debo resaltar que parece ser el primero de la historia de España que se ha asentado definitivamente en la conciencia de los ciudadanos. Prueba de ello fue el abrumador refrendo que recibió el 6 de diciembre de 1978, y la repulsa generalizada del pueblo español al intento de golpe de Estado de febrero de 1981, que pretendió adentrar en el oscurantismo de los tiempos los logros democráticos conseguidos por todos los españoles, y recogidos en la Constitución.

El estudio de la Constitución bajo una perspectiva sociológica lleva a afirmar que la forma del Estado en ella configurada es la que se corresponde con la sociedad de nuestro tiempo. Imagínense ustedes que a finales del siglo XX la Constitución hubiese reconocido un Estado liberal clásico, el cual se basa en la trilogía francesa de dejar hacer, dejar pasar, no inmiscuirse en los asuntos de la sociedad. Hoy día eso no es posible. La economía, la cultura, el progreso están relacionados con la actuación del Estado. $Y$ no sólo en España, sino en todo el occidente, porque la participación del Estado en la vida de los ciudadanos es imprescindible para conseguir el mayor grado de bienestar de los mismos. Por eso, la Constitución en su artículo 1 dice que España se constituye en un Estado social y democrático de derecho. Social, porque interviene en la vida de los ciudadanos de la forma antes dicha; democrático, porque establece la separación de pode- 
res y las elecciones para que el pueblo (en el que reside la soberanía nacional) elija a sus representantes políticos; y de derecho, porque la Constitución obliga a todos los ciudadanos y a los poderes públicos a respetar las normas que en ella se establecen y las leyes que la desarrollen.

La forma de gobierno es la monarquía parlamentaria. Este tipo de monarquía supone una superación de la monarquía constitucional, que no significaba más que el hecho de que en un país se daba la existencia de la monarquía y de una constitución a la que aquélla se sometía. Con la expresión monarquía parlamentaria se quiere decir mucho más. Significa la plena vigencia de los principios parlamentarios que consiste, fundamentalmente, en el principio de separación de poderes, el principio representativo y el principio de legalidad, como han recordado Lalumière y Demichel.

Nos encontramos en un sistema que configura la plena responsabilidad política del poder ejecutivo ante el parlamento. El juego parlamentario se desarrolla como la competencia entre dos poderes, ejecutivo y legislativo, sin la intervención del rey, que se coloca como poder moderador respecto a los otros órganos del Estado.

En la declaración y protección de los derechos encontramos de nuevo el factor sociológico antes mencionado. Los derechos que reconoce la Constitución española' no son sólo los individuales y tampoco los tradicionales. Va más allá, como le corresponde a cualquier texto que quiera regular la vida de la sociedad de su momento y que no se aferra a esquemas pasados, ni se adelanta al porvenir.

Entre los derechos civiles destaca la igualdad ante la ley de todos los españoles, sin que pueda prevalecer discriminación por razón de sexo, raza, nacimiento o religión. Lo cual conlleva a reconocer la libertad de cultos (por la que tanto han luchado los sectores más progresistas de este país) y la aconfesionalidad del Estado (consecuencia lógica de un planteamiento serio de lo que deben ser las relaciones Iglesia-Estado, que sin duda han madurado tras la declaración de aconfesionalidad).

La Constitución prohíbe la pena de muerte y reconoce el derecho a la vida $y$ a la integridad física $y$ moral, prohibiendo la tortura y las penas humanas y degradantes. Novedad en el reconocimiento de derechos, al no limitar aquéllos a la integridad física, y extenderlos a la moral y psíquica.

Se reconoce también en cuanto a derechos civiles el derecho al honor y a la intimidad personal y familiar, y el derecho a la propia imagen. Aspecto este último novedoso $y$ que se ha reflejado ante la posibilidad de que las nuevas tecnologías se inmiscuyan en la vida de la persona sin su permiso.

Seguiríamos enumerando la larga lista de los numerosos derechos reconocidos en nuestra Constitución. Creo que no es necesario porque todos los conocemos perfectamente. Mi intención ha sido enumerar algunos de los novedosos, solamente. 
La Constitución, sin embargo, es tradicional a la hora de configurar el legislativo. Las Cortes son bicamerales, compuestas por el Congreso de los Diputados y el Senado, si bien se debe reconocer que el Senado ha perdido su carácter histórico para tener un nuevo cometido, acorde con el Estado de las Autonomias. El Senado es definido como cámara de representación territorial, y una vez en marcha las comunidades autónomas su objetivo primordial es servir de portavoz a cada una de ellas, permitiendo que a él lleguen las inquietudes y propuestas de las comunidades autónomas, que no tienen cabida en el Congreso, el cual representa directamente a todos los ciudadanos espanoles, y no a las nacionalidades - regiones donde residan. Prueba del carácter territorial del Senado es la posibilidad contemplada en la Constitución de que cada comunidad autónoma designe a un senador que la represente directamente y a otro más por cada millón de habitantes.

Al introducir la breve historia del constitucionalismo español, que acabo de perfilar en el apartado anterior, dije que en cada etapa constituyente se habian planteado unas constantes ya históricas. La primera era las relaciones Iglesia-Estado que ya hemos visto cómo se han resuelto al proclamar la Constitución de 1978 la aconfesionalidad del Estado, la libertad de cultos y el reconocimiento expreso a la Iglesia Católica. Proclamación que no ha creado ningún trauma social y que ha resuelto de forma rotunda los viejos problemas que planteó en el siglo pasado y principios del actual.

La segunda constante era la forma de gobierno, que en la actualidad se configura como monarquía parlamentaria, cuyos rasgos antes he enumerado.

La tercera se refería al reconocimiento de los derechos individuales y a su garantía. Nuestra constitución va más allá del reconocimiento de los derechos individuales, es decir, de cada individuo, los cuales son además enumerados pormenorizadamente en el Título $I$, el cual incluye también a las libertades públicas tales como la libertad de expresión, de información, de cátedra, etc.

Cabe decir, en cuanto a la garantía de estos derechos que la Constitución regula un sistema eficaz y seguro para que sean ejercidos por los ciudadanos, al tiempo que se le impide a los poderes públicos que los conculquen. Los llamados derechos y libertades de carácter negativo; esto es, los que suponen la abstención de los poderes páblicos, vinculan a éstos desde el momento en que están enunciados en la Constitución. Sólo por ley, que deberá respetar siempre el contenido de los mismos, podrá regularse el ejercicio de tales derechos y libertades.

Los derechos que suponen una actuación positiva del Estado o de algunos de sus órganos, contenidos bajo el nombre de "principios" en el capitulo III del Título I informarán la legislación positiva, la práctica judicial 
y la actuación de los poderes públicos, y sólo podrán ser alegados ante la jurisdicción ordinaria de acuerdo con lo que dispongan las leyes que los desarrollen, según dispone el artículo 53.3 de la Constitución. Estos derechos no son exigibles inmediatamente, sino que son unos principios que la Constitución ofrece como inspiración en la que deberán basarse e inspirarse las leyes y la práctica política.

En cambio, los derechos de carácter negativo, sí son exigibles por los ciudadanos y éstos podrán recabar la tutela ante los tribunales ordinarios, por un procedimiento basado en los principios de preferencia y sumariedad, y en su caso, a través del recurso de amparo ante el Tribunal Constitucional. Figura también nueva en la historia constitucional española.

Para el caso de que todo ello no pueda ser eficaz, cosa que dudo mucho por la perfección con que son protegidos los derechos y libertades públicas, los ciudadanos podrán dirigirse al Defensor del Pueblo para la defensa de los derechos comprendidos en el Título I, cualquiera que sea la naturaleza de estos derechos.

La última de las constantes es el regionalismo, el cual merece un capítulo aparte.

\section{EL PROBLEMA REGIONAL. SOLUCION ACTUAL Y SINTESIS HISTORICA. CEUTA Y MELILLA}

\section{1.--Solución actual}

El artículo 2 de la Constitución reconoce el derecho a la autonomía de las nacionalidades y regiones que integran la nación española. Por tanto, al hablar de la autonomía hemos de hacerlo desde la perspectiva de que es un derecho constitucional y que por tanto ninguna comunidad podrá ser privada de ella, si cumple los requisitos que para su acceso establece la Constitución en el Título VIII.

El precedente de la constitución de Comunidades Autónomas lo tenemos directamente en la Constitución de 1931. Es un derecho general, pues ninguna parte del territorio, incluidas Ceuta y Melilla, queda excluida de él; es voluntario, por cuanto no es impuesto, sino que la iniciativa la tienen determinados órganos del territorio; no es uniforme, sino que se pueden recoger las peculiaridades regionales; y es progresivo, en el sentido de que al cabo de cinco años las autonomías constituidas por el procedimiento del artículo 143 de la Constitución, pueden aumentar sus competencias.

El Estado se articula y organiza, según la Constitución, en municipios, provincias y comunidades autónomas y existen dos principios que han de cumplir todas ellas y en especial las comunidades autónomas. Es la soli- 
daridad efectiva entre todas ellas, y también la igualdad de los españoles, residan en el territorio que sea.

La diferencia que existe entre las comunidades constituidas por el procedimiento establecido en el artículo 143 de la Constitución y en el 151 es de sobra conocida, y no voy a extenderme sobre ello, pues su enumeración sería demasiado larga y a estas alturas de exposición temo aburrirles demasiado.

Si quiero resaltar que la conciencia regional en España no es algo nuevo, sino que tiene sus orígenes en el siglo XIX. Voy a referirme brevemente a ella.

\section{2.-Síntesis histórica}

El período comprendido entre 1812 y 1868 , es decir, desde la Constitución de Cádiz hasta la revolución llamada "Gloriosa" se caracteriza por una tendencia ininterrumpida hacia el centralismo y la uniformidad, basados ambos en el principio de unidad nacional. En 1833 se crea la provincia como unidad político-administrativa básica, en sustitución de las regiones históricas. En 1839 se suprimen los fueros vascos y navarros que garantizaban la autonomía política, legislativa y judicial de estas regiones.

Surge entonces un incipiente movimiento regionalista que pretendía la supervivencia de las regiones históricas y el retorno al gobierno descentralizado, restituyendo los fueros del País Vasco y de Navarra.

El descontento con la política centralista de la monarquía borbónica y la penetración del Romanticismo avivó el redescubrimiento y el renacimiento de las culturas regionales. Ello unido a la propagación de las ideas federalistas de $\mathrm{Pi}$ y Margall caracterizó el período de 1868 a 1874. Los movimientos regionalistas propugnaban la unidad en la diversidad y la creación de Estados regionales.

Entre 1874 y 1898 se vivió en España un cierto progreso económico y un crecimiento industrial que tornó el regionalismo en la defensa de los intereses materiales de cada región. Aunque en Cataluña, Galicia y País Vasco se desarrollaba una conciencia regional más general.

Tras la pérdida de las últimas colonias España sufrió una época de crisis, y entre los muchos problemas de entonces se encontraba el problema regional. Aumenta la participación catalana y vasca en la política nacional, pretendiendo obtener la autonomia para sus regiones de forma gradual y presionando desde dentro del sistema, en vez de desde fuera.

Tras el paréntesis de la dictadura de Primo de Rivera, el consenso entre los partidos republicanos liberales, el Partido Socialista y varias organizaciones políticas regionalistas se materializó en la fórmula de autonomía regional recogida en la Constitución de 1931. Por segunda vez en la historia contemporánea española predominó la unidad en la diversidad 
sobre el principio centralista. La Constitución de 1931 no era un proyecto federalista, pero permitía la creación de regiones autónomas si dos tercios de las poblaciones expresaban tal voluntad. Así nacieron los Estatutos de Autonomía de Cataluña en 1932 y del País Vasco en 1936.

Como indica López Aranguren en este periodo surge un nuevo problema regional. Junto a las aspiraciones tradicionales basadas en las diferencias lingüístico-culturales, comienzan a denunciarse en las regiones pobres y menos desarrolladas ciertos agravios comparativos y determinadas desigualdades de naturaleza económica.

Esto último es fundamental para comprender las componentes de la actual conciencia regional, que ha llevado a la constitución de 17 comunidades autónomas. Ya no se reivindica sólo por un sentimiento diferenciador en cuestiones culturales o lingü ísticas, sino que los territorios más pobres y menos desarrollados de España se han unido al proceso autonómico por considerarlo un medio para luchar contra la desigualdad y el subdesarrollo. Conviene tener esto en cuenta a la hora de enjuiciar las actuales componentes de la conciencia regional.

\section{3.-La autonomía de Melilla}

No quiero acabar esta conferencia sin hacer una mención expresa a la posible autonomía de Melilla, ciudad en la que nos encontramos, y a cuyo alcalde agradezco profundamente la atención que ha tenido conmigo, invitándome a dirigirles estas palabras.

La autonomía de Melilla está recogida en el artículo 144 de la Constitución y en su disposición transitoria quinta. Obviamente había que darle un trato especial, pues la técnica del legislador diferencia la casuística de aquellos territorios o provincias limítrofes con características históricas, culturales y económicas comunes o bien de aquellos territorios insulares o provinciales con entidad regional histórica. del caso de Melilla y de Ceuta.

El derecho a la autonomía de Melilla está recogido en la disposición transitoria quinta de la Constitución, que dice: "Las ciudades de Ceuta y Melilla podrán constituirse en Comunidades Autónomas si así lo deciden sus respectivos ayuntamientos, mediante un acuerdo adoptado por la mayoría abosoluta de sus miembros y si así lo autorizan las Cortes Generales, mediante una ley orgánica, en los términos previstos en el artículo 144." El cual habla de que las Cortes aprueben esa ley orgánica por motivos de interés nacional.

No se discute, pues, el derecho a la autonomía de Melilla, sino si las Cortes apreciarán los motivos de interés nacional.

A mi juicio, estos motivos se dan desde el momento en que hay una urganización territorial del Estado nueva, basada en los principios que 
antes hemos visto, y cuya última ratio es la total configuración del Estado de las Autonomías.

Antes he dicho que el derecho a la autonom fa significaba también el reconocimiento de las peculiaridades de cada territorio; es decir, que no es un derecho uniforme, por el cual cada comunidad deba tener la misma estructura y competencias que las otras. Al no ser así, nada impide elaborar un estatuto que recoja las peculiaridades de Melilla y de Ceuta. Ello es legal y técnicamente posible.

Muchas gracias por su atención. 